\title{
Akinetic Mutism due to Posterior Reversible Encephalopathy Syndrome in Pregnancy
}

\begin{abstract}
Ayas $\mathrm{ZO}^{1 *}$ and Öcal RO${ }^{2}$
${ }^{1}$ Department of Neurology, Sakarya University Training and Research Hospital, Sakarya, Turkey

${ }^{2}$ Department of Neurology, Başkent University, Ankara, Turkey

*Corresponding author: Zeynep Özözen Ayas, Department of Neurology, Sakarya University Training and Research Hospital, Sakarya, Turkey
\end{abstract}

Received: April 03, 2017; Accepted: April 21, 2017;
Published: April 28, 2017

Received: April 03, 2017; Accepted: April 21, 2017;
Published: April 28, 2017

\section{Introduction}

Posterior reversible encephalopathy syndrome (PRES) is a clinical entity characterized by headache, vomiting, altered consciousness, seizure, and visual loss. Hypertension is the most common reason, other known causes are pre-eclampsia, eclampsia, HELLP syndrome, immunosuppressive and cytotoxic drugs, collagen vascular diseases, thrombotic thrombocytopenic purpura, use of high dose steroid, kidney and liver failure, massive blood transfusion, HIV infection, intermittent porphyria, and organ transplantation. Brain magnetic resonance imaging (MRI) shows hyperintense edema area at T2 and fluid attenuated inversion recovery (FLAIR) sections and bilateral posterior supratentorial areas typically. In this article, we report anunusual case with akinetic mutism due to PRES which is secondary to eclampsia in 26 weeks of pregnancy and review the literature.

\section{Case Presentation}

A 27-year-old, right-handed woman with 30 weeks of pregnancy presented to the emergency department with generalized tonicclonic seizures occurring twice in half an hour. It was learned that, the patient had her first seizure at home. Her second seizure had been controlled with $5 \mathrm{mg}$ diazepam at the hospital. According to prenatal documentation, her pregnancy was normal. Her family noted that she had headache for 2 days, but she had no any medical examination. Her blood pressure was $160 / 80 \mathrm{mmHg}$. Her laboratory tests were normal except leukocutosis $(13,7 \mathrm{~K} / \mathrm{uL})$, and proteinuria in spot urine $(500 \mathrm{mg} / \mathrm{dl})$. Diagnosed with eclampsia, she underwent emergency cesarean section.

Her neurological examination had akinetic mutism like as unresponsiveness with open eyes, no spontaneously speech and move in the intensive care unit. She had normal optic disc, and normal pupillary reactions, nystagmus was present falling towards the direction of her sight in her bilateral horizontal sight. She had no motor or sensory deficits with normal tendon reflexes. Computerized tomography (CT) of the brain showed a bilateral hypodensity area in occipital lobe (Figüre 1). Hyperintense edema areas were detected at the bilateral frontal, posterior parietal and occipital areas in T2 and FLAIR sections in the cranial MRI (Figüre 2). Her MRI venography was normal. The patient was treated with antiedema and antihyperintensive theraphy following PRES diagnosis. She had still akinetic mutism and apathy $24^{\text {th }}$ hour later, but her nystagmus stopped. She had retrograde amnesia about last 2 days. Hypertension was controlled with intravenous glycerol trinitrate. Than she was treated with $10 \mathrm{mg}$ of amlodipine, $5 \mathrm{mg}$ of perindopril indapamid, $60 \mathrm{mg}$ of niphedypine, $12.5 \mathrm{mg}$ of carvedilol for oral medication. When her blood tension was controlled with oral medication, she was transferred from intensive care unit on the $4^{\text {th }}$ day. Having no additional problem detected in the hospital, the patient was discharged with antihypertensive and anticonvulsant treatment. Her control examination one month later had no akinetic mutism and MRI findings were back to normal.

\section{Discussion}

PRES is a common reversible clinical entity, which is characterized by headache, impaired consciousness, seizure, and vision disorders. PRES was firstly defined by Hinchey et al. in 1996 [1]. There are two probable hypotheses for pathophysiology of PRES. First one is the vasospasm, which arises from acutely increased blood pressure. It is suggested that, ischemia and cytotoxic edema occurs at the 'arterial border zone' areas due to cerebral vasoconstriction as a result of the sympathetic system stimulation following the acute hypertension seizures [2-4]. Regulatory disorders at arteriolar and capillary level, as well as thrombosis and fibrinoid necrosis are held responsible for its pathophysiology [5]. According to the endothelial dysfunction hypothesis, impaired central autoregulation may cause lesions characterized by vasogenic edema in bilateral central nervous system areas susceptible for regulatory derangement (both occipital lobes) in the first place, followed by brain stem, deep white matter, and junction of gray and white matter. Researchers suggest that, generally lesions of PRES depend more to vasogenic edema than cytotoxic edema [6]. On the other hand, some authors acknowledge that, acute increase of blood pressure lead to actual syndrome [7]. Hypertension is present in most cases. Although our patient did not have hypertension, her admission blood pressure was increased and diagnosed as eclamptic
Phys Med Rehabil Int - Volume 4 Issue 2 - 2017 ISSN : 2471-0377 | www.austinpublishing group.com Ayas et al. (C) All rights are reserved
Citation: Ayas ZO and Öcal RO. Akinetic Mutism due to Posterior Reversible Encephalopathy Syndrome in Pregnancy. Phys Med Rehabil Int. 2017; 4(2): 1114. 


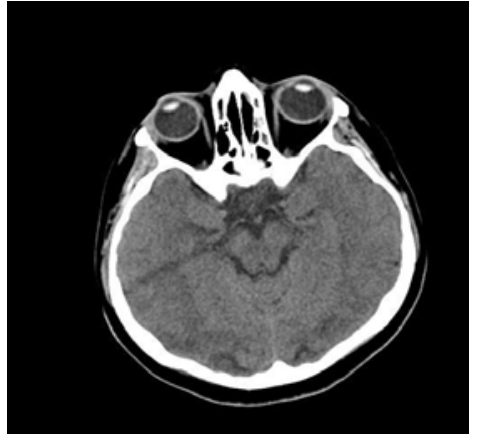

Figure 1: CT revealed bilateral hypodensity area in occipitallobe.
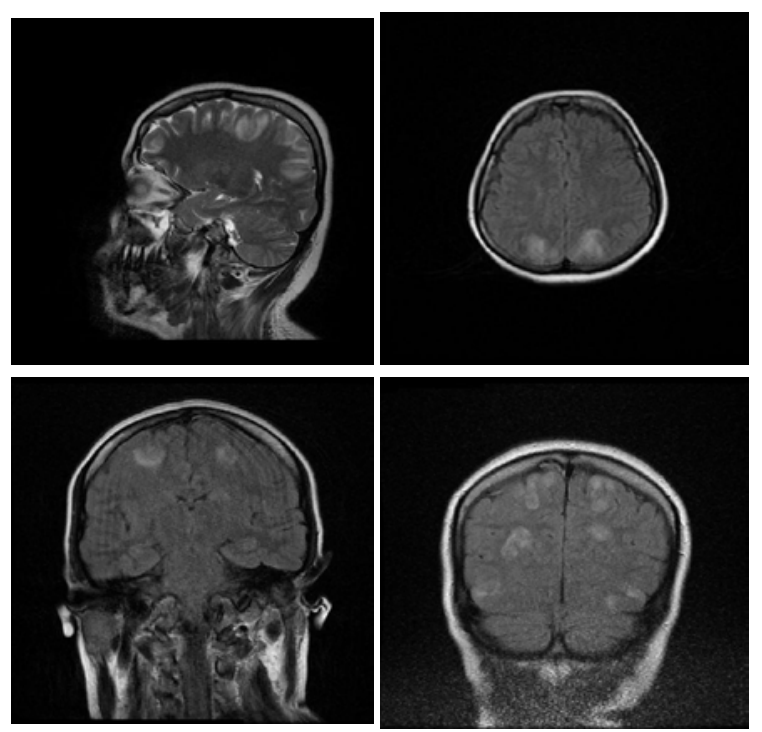

Figure 2: T2 and FLAIR MRI showed hyperintense edema areas in the bilateral frontal, posteriorparietal and occipital areas.

due to hypertension and seizure at her first arrival.

PRES' incidence and prevalence has not been reported in the literature, however, it has been found more frequently among female patients [8]. Eclampsia, and preeclampsia is a factor causing frequency of PRES among women. The studies detected eclampsia and preeclampsia may cause in $7 \%$ to $20 \%$ of PRES cases [1,9]. In a study, PRES was found in 18 patients of 39 pregnant women [10]. It generally occurs in the period between $28^{\text {th }}$ week and $13^{\text {th }}$ postpartum day [11]. PRES was diagnosed in the $30^{\text {th }}$ week of pregnancy of our patient.

Hypertension may develop due to such causes as eclampsia, preeclampsia, immunosuppressive agents, renal diseases, coeliac disease, porphyry, massive blood transfussion, sepsis, organ transplantation. Our patient was eclamptic women due to hypertension and seizure, as being the known risk factor for PRES.

Symmetrical hypodense areas in subcortical white matter in bilateral parieto-occipital lobes in CT or hyperintense edematous areas in T2 and FLAIR sections of MRI are classical neuroradiological findings. Gray matter is usually uninvolved. FLAIR and diffusion MRI characterize edema better and provides an early diagnosis. It may more rarely be found also at pons, cerebellum, and at other areas $[2,12]$. Frontal lob (\%68), temporal lob (\%40), cerebellum (\%30), basal ganglia, brain stem, and deep white matter may be involved (9). In our case, large bilateral parietal, occipital, and frontal areas have been detected. No correlation generally exists between type and intensity of clinical findings of the patients, and with the size of the lesions [13].

PRES is characterized by headache, impaired consciousness, seizure, and vision disorders. Our patient had seizure. In the study of Striano et al., 3000 cases having suffered seizure were examined retrospectively, and among 8 patients, PRES was detected in 5 patients due to eclampsia, and in 2 of them due to postpartum eclampsia [14].

Akinetic mutism is a sign, which the patient has unresponsiveness with open eyes, no spontaneously speech and move. It is seen in paramedian reticular formation lesions at bilateral nucleus caudatus, anterior singulat girus, frontal cortical, diencephalons. Numerous vascular, toxic, infectious, and degenerative diseases may bring along akinetic mutism. It is often misdiagnosed as depression, psychosis, and delirium. Our patient had akinetic mutism due to ischemia and edema related with PRES. We thought that when the lesions deacreased, akinetic mutism was regressed.

Control of blood pressure, treatment of seizures and electrolyte imbalance, if any, and delivery of the baby, or caesarean operation within the shortest time are recommended for the pregnant women with PRES. Treatment of etiologic cause is the basic principle in PRES. It is critical to eliminate hypertension and trigger factor. Average blood pressure should be lowered by $20-25 \%$ within the first $1-2$ hours, or diastolic blood pressure should be lowered to $100 \mathrm{mmHg}$. Rapidly decrease of blood pressure should be avoided due to the risk of organ dysfunction and ischemic infarct. Our patient was treated with multiple medical theraphy for controlling hypertension. Although tension values could have been controlled with the medication given in the first hour, but blood tension increaed again during monitoring. Postoperation, blood pressure control could have been maintained firstly by intravenous, then oral multiple antihypertensive treatment.

\section{Conclusion}

PRES is a syndrome, which may be diagnosed both clinically, and radiologically, and may usually be regressed by early diagnosis and treatment. But it may cause permanent brain damage and neurological sequels. In this study, an akinetic mutism may be caused by PRES, which is a rare clinical manifestation, is introduced.

\section{Concent}

The patient informed consent for the case report to be published.

\section{References}

1. Hinchey J, Chaves C, Appignani B, et al. A reversible posterior leukencephalopathy syndrome. N Engl J Med. 1996; 334: 494-500.

2. Stott VL, Hurrell MA, Anderson TJ. Reversible posterior leukencephalopathy syndrome: a misnomer reviewed. Intern Med J. 2005; 35: 83-90.

3. Vaughan CJ, Delanty N. Hypertensive emergencies. Lancet. 2000; 356: 411 417.

4. Rangi PS, Partridge WJ, Newlands ES, Waldman AD. Posterior reversible encephalopathy syndrome: a possible late interaction between cytotoxic agents and general anesthesia. Neuroradiology. 2005; 47: 586-590. 
5. Naidu K, Moodley J, Corr P, Hoffmann M. Single photon emission and cerebra computerised tomographic scan and transcranial Doppler sonographic findings in eclampsia. Br J Obstet Gynaecol. 1997; 104: 1165-1172.

6. Teksam M, Casey SO, Michel E, Truwit Cl. Posterior reversibl ensefalopati sendromu: Patofizyoloji ve ileri MRG teknikleri ile korelasyon. Tanısal ve Girişimesel Radyoloji. 2001; 7: 464-472.

7. Prasad N, Gulati S, Gupta RK, Kumar R, Sharma K, et al. Is reversible posterior leukencephalopathy with severe hypertension completely reversible in all patients? Pediatr Nephrol. 2003; 18: 1161-1166.

8. O'Hara McCoy H. Posterior reversible encephalopathy syndrome: an emerging clinical entity in adult, pediatric, and obstetric critical care. J Am Acad Nurse Pract. 2008; 20: 100-106.

9. McKinney AM, Short J, Truwit CL, et.al. Posterior reversible encephalopathy syndrome: incidence of atypical regions of involvement and imaging findings. AJR Am J Roentgenol. 2007; 189: 904-912.

10. Demirtas Ö, Gelal F, Vidinli B, et al. Preeklampsi ve eklampside kranial MR görüntüleme ve klinik korelasyon. Diag Interv Radio. 2005; 11: 189-194.
11. Legriel S, Pico F, Azoulay E. Understanding Posterior reversible encephalopathy syndrome. Annual update in intensive care and emergency medicine. 2011; 1631-1653.

12. Schwartz RB, Bravo sm, Klufas RA, Hsu I, Barnes Pd, et al. Cyclosporine neurotoxicity and its relationship to hypertensive encephalopathy: CT and MR findings in 16 cases. AJR Am J Roentgenol. 1995; 165: 627-631.

13. Fugate JE, Claassen DO, Cloft HJ, Kallmes DF, Kozak OS, Rabinstein AA. Posterior reversible encephalopathy syndrome: associated clinical and radiological findings. Mayo Clin Proc. 2010; 85: 427-432.

14. Striano $\mathrm{P}$, Striano $\mathrm{S}$, Tortora $\mathrm{F}$, et al. Clinical spectrum and critical care management of Posterior Reversible Encephalopathy Syndrome (PRES). Med Sci Monit. 2005; 11: 549-555.
Phys Med Rehabil Int - Volume 4 Issue 2 - 2017

ISSN : 2471-0377 | www.austinpublishing group.com

Ayas et al. (C) All rights are reserved
Citation: Ayas ZO and Öcal RO. Akinetic Mutism due to Posterior Reversible Encephalopathy Syndrome in Pregnancy. Phys Med Rehabil Int. 2017; 4(2): 1114 